\title{
Prevalence of paternal perinatal depressive mood and its relationship with maternal depression symptomatology: An Italian study
}

\author{
M. Caterina Cattaneo ${ }^{1 *}$, Elena A. Macchi ${ }^{1}$, Roberta Salerno ${ }^{1}$, Valentina Chiorino ${ }^{1}$, Sara Roveraro ${ }^{1}$, \\ Francesco Barretta ${ }^{2}$, Camilla B. Fontana ${ }^{3}$, Fabio Mosca, Prof ${ }^{3}$ \\ ${ }^{1}$ Perinatal Psychology and Post-Partum Unit, Consultorio Familiare Accreditato ASL “Genitori Oggi”-CAV Mangiagalli, Milan, Italy \\ ${ }^{2}$ Department of Clinical Sciences and Community Health, University of Milan. Epidemiology Unit, Department of Preventive Medicine, \\ Fondazione IRCCS Cà Granda- Ospedale Maggiore Policlinico, Milan, Italy \\ ${ }^{3}$ NICU, Fondazione IRCCS Cà Granda - Ospedale Maggiore Policlinico, Università degli Studi di Milano, Milan, Italy \\ *Corresponding author E-mail: mcaterinacattaneo@gmail.com
}

\begin{abstract}
Background: Literature shows that the birth of a child is a vulnerability moment for the mental well-being of both parents.

Objectives: estimate the prevalence of a depressive symptomatology in an Italian sample of new fathers during the first six months postpartum and provide its association with maternal mood.

Methods: 244 neo- parents filled the Italian version of the Edinburgh Postnatal Depression Scale (EPDS) and a General Information Questionnaire between 2/5 days after delivery during the hospitalization in the Mother-infant Department of an Italian hospital and after 2 and 6 months postpartum by mailed.

Results: in the first week postpartum, $6.65 \%$ of fathers had a EPDS score $\geq 10$, this percentage decreases to $2.63 \%$ at 2 months and $2.59 \%$ at 6 months postpartum. Previous history of anxiety/panic attacks in fathers was a risk factor for a depressive symptomatology of them after 2 and 6 months postpartum. Paternal and maternal depressive mood were correlated most of the times and associated especially after births when a depressed father is more than 5 time frequently associated to a depressed mother 2 months later.

Conclusions: experimental data suggest that neo-fathers experiment depressive symptoms especially in the immediate postpartum when their mood is associated with maternal mood in a significant way. Health care professionals should pay great attention to the neo-parental couple mood.
\end{abstract}

Keywords: EPDS; Maternal Mood; Paternal Perinatal Depression; Parental Couple; Screening.

\section{Introduction}

The birth of a child is a vulnerability moment for the mental wellbeing of both parents, the passage known in psychology as the "transition to parenthood" developed a great redefinition of personal spaces and functions for a new mental state in partners (Cowan \& Cowan 1992; De Magistris et al. 2013).

Postanal Depression in mothers is wide studied in literature, about from $10 \%$ to more than $20 \%$ of women suffered from these disorders during the postpartum period (Burt \& Stein 2002).

Also for men, the birth of a new baby can be seen as a stressful time and their emotional involvement can lead to depression symptoms or distress in similar ways to what happens to mothers (Matthey et al. 2001). Moreover, the psychological vulnerability of neo-fathers has been overlooked for a long time, and it has been little studied as compared with maternal mental-health (Solantaus \& Salo 2005).

In the last ten years, researchers have shown interest in studying the phenomenon of Paternal Perinatal Depression (PPD) which can affect the emotional state of the fathers from pregnancy to the first year of life of the child (Luca \& Bydlowsky 2001; Matthey et al. 2001; Edhborg et al. 2005; Pinheiro et al. 2006; Goodman
2008; Currò et al. 2009; Gao et al. 2009; Van der berg et al. 2009; Baldoni \& Ceccarelli 2010; Nishimura \& Ohashi 2010; Figuereido \& Conde 2011).

Literature shows the main predictors of postpartum depression in men were identified as: a personal story of depression or anxiety during pregnancy (Areias et al. 1996; Matthey et al. 2000; Wee et al. 2011), a depressive mood in partner either prenatally or during postpartum period (Zelkowitz \& Milet 2001), couple relationship (Matthey et al. 2000) and high level of stress (Buist et al. 2002; Condon et al. 2004).

However, having a partner with elevated depressive symptoms or depression is the most important predictive factor of perinatal depression in fathers (Goodman 2004; Schumacher et al. 2008; Wee et al. 2011).

Literature reports that the incidence of PPD during the first postpartum year can vary from $1.2 \%$ to $25.5 \%$ in community samples and from $24 \%$ to $50 \%$ among men whose partners have developed a postpartum depression (Goodman 2004). A recent meta-analysis of Paulson and Bazemore (2010) showed that the prevalence of paternal depression between first trimester of pregnancy and oneyear postpartum was approximately $10.4 \%$ (95\% [CI], $8.5 \%$ $12.7 \%$ ) and that fathers experienced the highest rates of depression 3 to six months postpartum. 
This heterogeneity in percentages observed among rates on PPD reflects differences in methods and timing of assessment used, sample sizes and different tools and cut-off scores (Paulson \& Bazemore 2010).

\subsection{Correlation between paternal and maternal perinatal depression}

Literature reports consistent data about a lower rate of mood disturbance in men compared with women (Paulson \& Bazemore 2010). Most researchers confirmed that mental states of partners are correlated during the perinatal period with important implications for family health and well-being (Goodman 2004).

Several studies showed that father's mental health is associated with increased maternal depression and infant problems of adaptation and communication between child and parents (Jacob \& Johnson 1997; Ramchandani et al. 2011; Weitzman et al. 2011).

However, the directionality of causal influence between the two clinical conditions is not clear and recent theories sustain that is not only the maternal depression influenced paternal mood but also the contrary (Baldoni 2005). Fathers who are worried, very anxious or depressed may adversely affect the emotional state of their partner (Luca \& Bydlowsky 2001; Baldoni 2005).

\subsection{Objectives}

The purpose of this longitudinally study was focalized the attention on paternal perinatal depression symptomatology and its association with mental state of partner.

In a broader view we wanted to wide the knowledge about the phenomenon of PPD in Italy where it hasn't been widely studied (Baldoni et al. 2009; Currò et al. 2009).

The aims of this work: 1) estimate the prevalence of a depressive symptomatology in an Italian sample of new fathers using EPDS during the first six months postpartum and describe its course 2) to provide associations between depression symptomatology and socio-demographic information 3) describe the relationship between paternal and maternal depressive mood.

\section{Method}

\subsection{Participants}

The sample is part of a longitudinal research focused not only on the postnatal depression symptomatology but also on the clinic depression and the parental stress in new parents that comprehend the administration of several tests.

122 couples of first-time parents were recruited in the Mother and Infant Department of an Italian Hospital in Milan, between the 2 and the five day postpartum.

Inclusion criteria were having their first child, being Italian by birth and residence, and having at least 18 years. 114 (93, $44 \% \%)$ fathers and $122(100 \%)$ mothers returned the EPDS also at 2-3 months postpartum, while 119 men (97.54\%) and 119 (97.54\%) women completed EPDS after six months.

Globally $111(90,98 \%)$ neo-fathers and 119 neo-mothers $(97.5 \%)$ completed all three steps of the study.

\subsection{Measures}

\subsubsection{General information questionnaire}

Data on social and demographic characteristics and psychological variables were collected 2-5 days postpartum, with a General Information Questionnaire specifically realized ad hoc by the researchers. The questionnaire included items on age, occupation, education, information about people you live with; previous history of anxiety or panic attacks and also thoughts about the arrival of the baby were investigated.
Questionnaire was the same for mothers and fathers, nonetheless, for the propose of this paper, only men socio-demographic and psychological variables will be reported and analysed.

2.2.2. Edinburgh postnatal depression scale (EPDS, Cox et al. 1987)

Couples complete Edinburgh Postnatal Depression Scale (Cox et al. 1987), a 10-item self-report questionnaire specifically designed to assess perinatal depression symptomatology in women but also used for men and in many longitudinal studies (Matthey et al. 2001; Edmonson et al. 2010; Figuereido \& Conde 2011). A cutoff score of $9 / 10$ has been recommended by Matthey et al. 2001 to detect postnatal major o minor depression in men with a sensitivity of $71.4 \%$ and a specificity of $93.8 \%$, while in women, the same cut-off is suggested like a screening measure in the postpartum period (Cox et al. 1987). For this study, an EPDS total score $\geq 10$ has been used to detect a depressive symptomatology both in fathers and in mothers. This cut-off has already been used in other studies which investigated PPD and couple morbidity (Buist et al. 2002; Edhborgh 2008; Figuereido \& Conde 2011; Gawlik 2014).

\subsection{Procedure}

Eligible couples were recruited in the Mother and Infant Department of Fondazione Ca' Granda, IRCCS Ospedale Maggiore Policlinico, Milan, Italy, by the team of psychologists and psychotherapists of the Family Service, Consultorio Familiare "Genitori Oggi".

Between the 2 and the 5 days postpartum, during the hospitalization, couples were asked to complete the Italian version of the EPDS (Benvenuti et al. 1999) and the General Information Questionnaire independently from each other (first assessment). After 2 months (second assessment) and 6 months postpartum (third assessment) EPDS questionnaire was mailed to the couples. If the questionnaires did not return within two weeks of mailing, a reminder telephone call was provided. Furthermore, every subject with EPDS score over cut-off or with affirmative answer at item number 10 ("suicidal thoughts") was called for a psychological interview.

The study was approved by the local ethics committee of Consultorio Familiare "Genitori Oggi". Participation at this study was voluntarily and individual written informed consent was obtained for all.

\subsection{Statistical analysis}

To describe sample characteristics and EPDS tests results usual descriptive statistics were used (mean, SD, absolute and relative frequencies, median and IQR).

To assess the association between categorized and not categorized test results and socio-demographic variables we perform Fisher's Exact and Wilcoxon Test, respectively.

To investigate the association between depressive mood of fathers and mothers between time Fisher Exact Test was implemented and in order to quantify the significant results, we used logistic regression models. All tests are two-sided, and a p-value lower than 0.05 was considered significant. All the analyses were implemented with the program SAS 9.2, SAS Institute Inc., Cary, NC.

\section{Results}

\subsection{Fathers' characteristics}

The mean age of the men who participated at this study was 36.84 $(\mathrm{SD}=5.27)$, with a range between 25 and 50 years. All men lived with their partner (1missing answer), 91.7\% ( $\mathrm{N}=105)$ had a high level of education (high school or university) and 58.3\% ( $\mathrm{N}=63)$ works like employee/teacher. About psychological variables, 5\% $(\mathrm{N}=6)$ of fathers had a previous history of depression while 
$11.9 \%(\mathrm{~N}=14)$ reported to have suffered from panic or anxiety attacks in the past.

Moreover, $75 \%(\mathrm{~N}=90)$ of fathers have defined the arrival of the baby like "conceived and desired for a long time," $15 \%(\mathrm{~N}=18)$ "unexpected, but welcomed," $8.33 \%(\mathrm{~N}=10)$ "looked for a long time" and $1.67 \%(\mathrm{~N}=2)$ "unexpected". All socio-demographic and psychological characteristics of fathers in time and EPDS results are described in Table 1.

\subsection{EPDS score}

The mean fathers' EPDS score at 2/5 days postpartum, at two and six months postpartum were respectively $3.49(\mathrm{SD}=3.38) ; 2.36$ $(\mathrm{SD}=2.65) ; 2.42(\mathrm{SD}=2.73)$.

From the analysis emerged that $6.65 \%(\mathrm{~N}=8)$ of fathers had a EPDS score $\geq 10$ at $2 / 5$ days postpartum; this percentage

Table 1: Socio-Demographic and Psychological Variables in Fathers

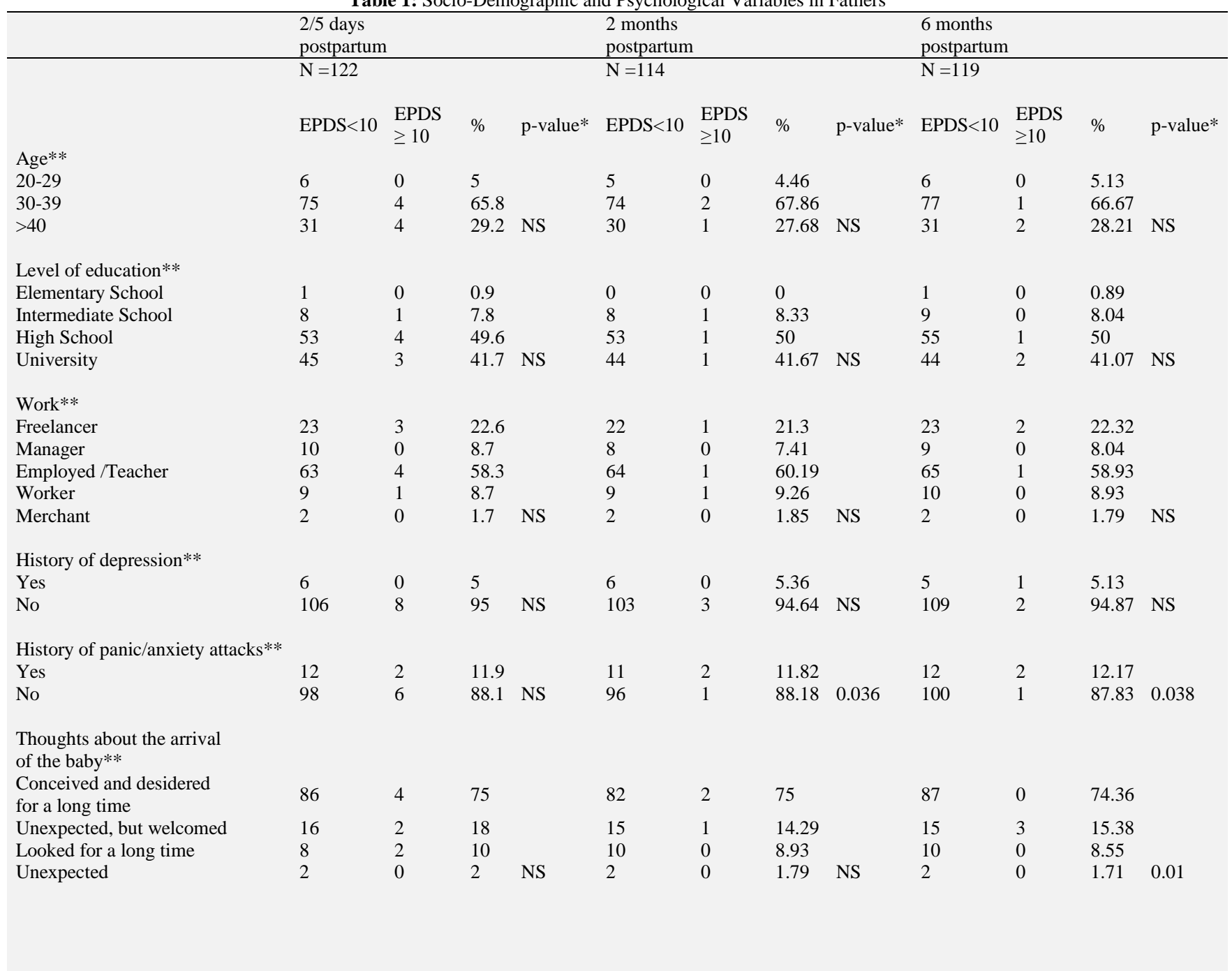

Note: $*$ p-value for Fisher Exact test

** Information is not available for all fathers

NS $=$ not significant $(\mathrm{p}>0.05)$

\subsection{Variable associated with paternal depression symp- tomatology}

How we can see in Table 1, none of the socio-demographic variables (age, level of education, work and previous history of depression) results significantly associated with a depression symptomatology (EPDS $\geq 10$ ) in fathers. Conversely previous history of panic or anxiety attacks presented a strong association with EPDS group at 2 months $(\mathrm{p}<0.04)$ and at six months postpartum $(\mathrm{p}=0.04)$.

Also the thoughts about the arrival of the baby showed a significant association with an EPDS class at 6 months postpartum $(\mathrm{p}=0.01)$.

Wilcoxon Test revealed also that fathers with a previous history of panic/anxiety attacks have significantly higher EPDS score in all three steps of the study than fathers who did not $(p<0.01$ at $2 / 5$ days; $\mathrm{p}<0.01$ at 2 months; $\mathrm{p}=0.01$ at 6 months). decreases to $2.63 \%(\mathrm{~N}=3)$ at 2 months and $2.59 \%(\mathrm{~N}=3)$ at 6 months postpartum. The mean score of EPDS over cut-off was very high, respectively $12.63(\mathrm{SD}=3.11) 10.33(\mathrm{SD}=0.57) 11.67$ $(\mathrm{SD}=0.57)$ in the three times of assessment.

On the other hand, mean of EPDS scores in fathers without a depressive symptomatology (EPDS $<10)$ were quite low: 2.85 ( $\mathrm{SD}=$ $2.30)$ at $2 / 5$ days, $2.15(\mathrm{SD}=2.34)$ after 2 months and 2.18 (SD $=2.30$ ) at six months postpartum.

All these data, with median score and IQR, too, are reported in Table 2. 


\begin{tabular}{|c|c|c|c|c|}
\hline & & $\begin{array}{l}2 / 5 \text { days } \\
\text { postpartum } \\
\mathrm{N}=122\end{array}$ & $\begin{array}{l}2 \text { months } \\
\text { postpartum } \\
\mathrm{N}=114\end{array}$ & $\begin{array}{l}6 \text { months } \\
\text { postpartum } \\
\mathrm{N}=119 \\
\end{array}$ \\
\hline \multicolumn{5}{|l|}{$\mathrm{N}, \%$} \\
\hline & $E P D S \geq 10$ & $8(6.56)$ & $3(2.63)$ & $3(2.59)$ \\
\hline & $E P D S<10$ & 114 (93.44) & $111(97.37)$ & $113(97.41)$ \\
\hline \multicolumn{5}{|l|}{ Mean,(SD) } \\
\hline & TOT. & $3.49(3.38)$ & $2.37(2.65)$ & $2.42(2.73)$ \\
\hline & $E P D S \geq 10$ & $12.63(3.11)$ & $10.33(0.57)$ & $\begin{array}{l}11.6 / \\
(0.57)\end{array}$ \\
\hline & EPDS $<10$ & $2.85(2.30)$ & $2.15(2.34)$ & $2.18(2.30)$ \\
\hline \multirow{3}{*}{ Median,(IQR) } & TOT. & $3(1-5)$ & $2(0-4)$ & $2(0-4)$ \\
\hline & $E P D S \geq 9$ & $12.63(10-14)$ & $\begin{array}{l}10.33(10- \\
11)\end{array}$ & $12(11-12)$ \\
\hline & EPDS $<9$ & $3(1-5)$ & $2.15(0-3)$ & $2.18(0-4)$ \\
\hline
\end{tabular}

We also assessed the association of the paternal mood over time using Spearman Correlation Coefficient. The results showed the EPDS score in the immediate postpartum period presented a high positive correlation with EPDS score at 2 months postpartum $(\mathrm{s}=$ $.577 ; \mathrm{p}<0.01)$ and with EPDS score at 6 month postpartum $(\mathrm{s}=$ $.461 ; p<0.01)$. Furthermore, EPDS score at 2 months correlated positively with EPDS score at 6 months postpartum $(\mathrm{s}=.568$; $\mathrm{p}$ $0.01)$.

\subsection{Associations between fathers and mothers EPDS results over time}

Spearman correlations coefficients showed that EPDS scores of fathers, and mothers were positively correlated in all of the points of assessment, only one in a borderline manner (see Table 3).

Table 3: Spearman's Correlations Coefficients between EPDS Score of Mothers and Fathers at All Time.

\begin{tabular}{|c|c|c|c|}
\hline & $\begin{array}{l}\text { EPDS 1 Mothers } \\
\text { (p-value)* }\end{array}$ & $\begin{array}{l}\text { EPDS 2 Mothers } \\
\text { (p-value)* }\end{array}$ & $\begin{array}{l}\text { EPDS } 3 \text { Mothers } \\
\text { (p-value)* }\end{array}$ \\
\hline $\begin{array}{l}\text { EPDS } 1 \text { Fathers } \\
\text { (p-value)* }\end{array}$ & $\begin{array}{l}0.40 \\
(<0.01)\end{array}$ & $\begin{array}{l}0.31367 \\
(<0.01)\end{array}$ & $\begin{array}{l}0.27 \\
(<0.01)\end{array}$ \\
\hline $\begin{array}{l}\text { EPDS } 2 \text { Fathers } \\
\text { (p-value)* }\end{array}$ & $\begin{array}{l}0.28 \\
(<0.01)\end{array}$ & $\begin{array}{l}0.38 \\
(<0.01)\end{array}$ & $\begin{array}{l}0.29 \\
(<0.01)\end{array}$ \\
\hline $\begin{array}{l}\text { EPDS } 3 \text { Fathers } \\
\text { (p-value)* }\end{array}$ & $\begin{array}{l}0.24 \\
(<0.01)\end{array}$ & $\begin{array}{l}0.18 \\
(0.06)\end{array}$ & $\begin{array}{l}0.40 \\
(<0.01)\end{array}$ \\
\hline
\end{tabular}

$* \mathrm{p}$ - Value for Spearman correlation coefficients

Analysis reported in Table 4 revealed that after 2/5 days and 2 month postpartum EPDS class results of mothers and 2/5 days postpartum EPDS class results of fathers are significantly associated. We have calculated that a depressed partner at the time of the first evaluation is more than 10 times frequently associated to another depressed one (OR: 11.9; 95\% CI: 2.2 - 62.7; p < 0.01) and a depressed father in the immediate postpartum is more than 5 time frequently associated to a depressed mother 2 months later (OR: 6.6; 95\% CI: $1.5-29.3 ; \mathrm{p}=0.01$ ).

Couple morbidity was also assessed by calculating the percentage of both members of a couple having high scores (EPDS $\geq 10)$ at each of assessment points.

The prevalence of couples who were in danger to suffer from depression (mothers and father with $\mathrm{EPDS} \geq 10)$ was $4.92 \%(\mathrm{~N}=6)$ in the immediate postpartum, $0.88 \%(\mathrm{~N}=1)$ at 2 month and 0 at 6 months. In particular, it is interesting to note that in the first time of assessment $75 \%$ ( 6 on 8 ) of fathers with an EPDS $\geq 10$, had also a depressed partner, while only $20.18 \%$ (6 on 29 ) of "depressed" mothers had also a partners with a EPDS score of 10 or more (see Table 4).

However if we consider couples of the sample, in which one or both partners presented a depressive symptomatology, the percentages decrease: in particular in the first step $25,41 \%(\mathrm{~N}=31)$ of couples have at least one "depressed" partner, $17.54 \%(\mathrm{~N}=20)$ at 2 months, and $12.07 \%(\mathrm{~N}=14)$ at 6 months postpartum (Fig. 1).

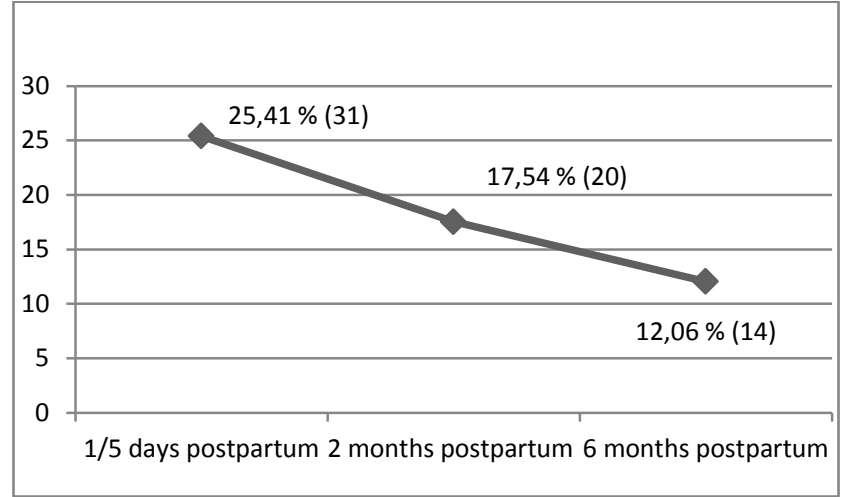

Fig. 1: Percentages of Couples with at Least One Depressive Partner.

\section{Discussion}

The prevalence rate of paternal postnatal depressive symptoms in our sample was lower than the rate mentioned in the meta-analysis of Paulson and Bazemore, 2010 (10\%) but globally included in the wide range of incidence (from $1.2 \%$ to $25.5 \%$ ) of PPD, during the first postpartum year, reported by the review of Goodman (2004). We found that $6.56 \%$ of neo-fathers presented a depressive symptomatology (EPDS $\geq 10)$ in the immediate postpartum comparable with the rate of PPD found by Figuereido \& Conde (2011), which found a $7.5 \%$ of men with an EPDS score $\geq 10$ in the first week postpartum. Conversely others studies, reported different percentages of PPD in the immediate postpartum period, lower (Edhborg $2008,1.8 \%$ ) or higher (Johnson \& Baker 2004, 8.61\%; Baldoni et al. 2009, 9\%), and among that, there is the Italian study of Currò et al. 2009, who reported that $12 \%$ of fathers were at risk of PPD in the first week postpartum and the $9.1 \%$ after 5 weeks using an EPDS $\geq 8$.

At 2 months postpartum, the percentage of fathers with depressive symptoms in our sample decreases to $2.63 \%$ which is higher than the result found by Edhborg in 2008 who found $1.8 \%$ of men with EPDS $\geq 10$, but lower than others studies using an EPDS cut-off of 9/10 (Morse et al. 2000, 6\%; Figuereido \& Conde 2011, 7.2\%; Gawlik et al. 2014, 7.8\%).

No many studies have investigated men's depressive symptoms six months after the birth using EPDS questionnaire; nevertheless the percentage of $2.59 \%$ in this study is once again lower than those reported by other studies that have investigated DPP during the first postpartum year (Ramchandani et al. 2008a; EscribàAgüir \& Artazcoz 2011).

Considering that EPDS could be a valid instrument to detect "blues" symptoms both in mothers and fathers (Edhborg 2008), our results may be interpreted like a presence of blues feelings in men in the immediate postpartum. The higher percentage of fathers with and EPDS $\geq 10$ between 2 and 5 days postpartum than the others' steps of assessments, seems to indicate a men response to birth as a stressful experience. In consistent with our conclusion, also other studies have revealed that fathers could suffer from baby blues during the first postpartum week, although in a milder way than mothers (Edhborg et al. 2005; Edhborg 2008).

If we compare EPDS mean scores of fathers with a depressive symptomatology (EPDS $\geq 10)$ and those who did not (EPDS $<10$ ), data seem polarized in all three steps: very low when below cutoff $\left(1^{\circ}\right.$ assessment: $\mathrm{M}=2.85 ; 2^{\circ}$ assessment $\mathrm{M}=2.15 ; 3^{\circ}$ assessment $\mathrm{M}=2.18)$ and very high when above cut-off $\left(1^{\circ}\right.$ assessment $\mathrm{M}=12.63 ; 2^{\circ}$ assessment $\mathrm{M}=10.33 ; 3^{\circ}$ assessment $\mathrm{M}=11.63$ ).

Fathers seem to recognize anxious or depressed feelings only when symptoms have already advanced and are no longer deniable. These scores may be interpreted as a "defense attitude" in men, they probably did not admit their feeling, or they expressed to disturb affect through different symptoms than those assessed in diagnostic interviews or self-report questionnaire (Wilhelm et al. 1998; Matthey et al. 2000).

As far as risk factors associated with PPD are concerned, none of socio-demographic variables (age, level of education, work and 
previous history of depression) results significantly associated with a depression symptomatology in fathers. Contrary to the main results reported in literature (Goodman 2004), also a past personal history of depression is not an important predictor for postpartum depressive symptoms in neo-fathers (Edhborg et al. 2005).

Previous history of anxiety/panic attacks, instead, resulted associated with high scores of EPDS in men, and they could be considered as a risk factor for a depressive symptomatology after 2 or six months postpartum. Others works found that paternal anxiety during pregnancy (Matthey et al. 2000; Ramchandani et al. 2008b) was associated with paternal depression in the months following the birth, nevertheless, we can't know specifically if the previous history of anxiety/panic attacks reported by fathers was related to pregnancy or to a previous period. However, we can affirm that fathers who have suffered from anxiety disorders, more or less acute, are more vulnerable to develop depressive symptoms in postpartum period.

According to literature, paternal and maternal depressive mood was positively correlated most of the times of assessments (Goodman 2004; Paulson \& Bazemore 2010). Moreover, significant associations between fathers and mothers depressive symptomatology (EPDS $\geq 10$ ), was revealed only in the immediate postpartum period $(\mathrm{p}<0.01)$. At $2 / 5$ days postpartum if one partner presented an EPDS score of ten or more; the other one had approximately an 11 times higher risk to be depressed too.

This great association did not occur in the other two times of assessment, so the immediate postpartum period seemed to be the most vulnerable time for the couple morbidity.

In this time, according to literature, depression in one partner is the biggest risk factor of depression in the other one (Baldoni et al. 2009; Wee et al. 2011). The great association between EPDS couple scores in the immediate postpartum, seems to suggest that the birth is a crisis event for the emotional well-being of both parents, and we can assume the existence of couple baby blues in which the mood of each partner affects the other (see Table 4).

This can also be confirmed by the high percentage $25.41 \%$ ( $\mathrm{N}=31$ ) of couples in which at least one parent experienced a postpartum depression symptomatology $2 / 5$ days after the delivery. Despite this, maternal mood had the greatest weight in determining this percentage of couples because mothers suffered more frequently from depressive symptomatology (EPDS $\geq 10$ ) than fathers in the puerperium induced also by hormonal changes (Table 4).
About the influence of depressive mood of each partner in the three times of assessments, we found that father's mood at $2 / 5$ days postpartum is associated with maternal mood at two months $(\mathrm{p}=0.01)$. A father with a depressive symptomatology in the immediate postpartum $(E P D S \geq 10)$ had more than five times higher possibility to have a "depressive" partner (EPDS $\geq 10$ ), two months later.

A similar temporal influence had already been found by Edhborg and his colleagues (2005), who showed that baby blues in partners, measured between 1 and 5 days post birth was a predictor for high EPDS scores at 2 months in both mothers and fathers.

These results seem to confirm recent theories according to which a depressed or anxious father isn't able to carry out the same functions of protection and security towards his partner (Baldoni 2005).

So the negative influence that paternal depression has on maternal mood in the months following the delivery, can be interpreted as a fail of that father's important basic protective function towards the mother to permit also a good adjustment between herself and the baby (Luca \& Bydlowsky 2001; Baldoni 2005).

\section{Conclusion and clinical implications}

Consistent with literature, EPDS questionnaires filled in by men, turned out to be a useful screening tool for health professionals to recognize the early signs of an affective disorder. However, it is necessary to take into account that depressive symptoms in men are not so easily distinguishable from the anxious ones and that fathers tend to little recognize and manifest them (Matthey et al. 2000).

This study has shown that neo-fathers experiment depressive symptoms especially in the immediate postpartum when their mood is associated with maternal mood in a significant way. The birth itself seems to be a crisis moment for the couple more than the following months and paternal depressive symptomatology may be a risk factor for maternal mood in the months after the delivery. Therefore, just from the hospital, the emotional wellbeing of the father should not be underestimated since it is directly connected to one of the mothers and more specifically to the couple well-being. Taking care of the woman in the period immediately after the delivery, means also, if it is possible, looking after the neo-parental couple.

Table 4: Association between Mothers and Fathers EPDS Class Results at All Time

\begin{tabular}{|c|c|c|c|c|c|c|c|c|c|}
\hline \multirow[b]{3}{*}{ Mothers } & \multicolumn{8}{|c|}{ Fathers } & \multirow[b]{3}{*}{ p-value* } \\
\hline & \multicolumn{2}{|c|}{$2 / 5$ days $\mathrm{P}, \mathrm{N}(\%)$} & \multirow[b]{2}{*}{ p-value* } & \multicolumn{2}{|c|}{2 months $\mathrm{P}, \mathrm{N}(\%)$} & \multicolumn{3}{|c|}{6 months P, N (\%) } & \\
\hline & EPDS <10 & EPDS $\geq 10$ & & EPDS $<10$ & $E P D S \geq 10$ & p-value* & EPDS $<10$ & $\mathrm{EPDS} \geq 10$ & \\
\hline \multicolumn{10}{|c|}{$2 / 5$ days, $\mathrm{N}(\%)$} \\
\hline EPDS <10 & $91(74.59)$ & $2(1.64)$ & & 85 (74.56) & $1(0.88)$ & & 89 (74.79) & $1(0.84)$ & \\
\hline $\mathrm{EPDS} \geq 10$ & $23(18.85)$ & $6(4.92)$ & $<0.01$ & $26(22.81)$ & $2(1.75)$ & NS & 27 (22.69) & $2(1.68)$ & NS \\
\hline \multicolumn{10}{|c|}{2 months, $\mathrm{N}(\%)$} \\
\hline EPDS $<10$ & 99 (81.15) & $15(12.30)$ & & $94(82.46)$ & $2(1.75)$ & & $97(81.51$ & $3(2.52)$ & \\
\hline $\mathrm{EPDS} \geq 10$ & $4(3.28)$ & $4(3.28)$ & $<0.05$ & $17(14.91)$ & $1(0.88)$ & NS & $19(15.97)$ & $0(0)$ & NS \\
\hline \multicolumn{10}{|c|}{6 months, $\mathrm{N}(\%)$} \\
\hline EPDS $<10$ & $103(86.55)$ & $9(7.56)$ & & 97 (87.39) & $11(9.91)$ & & $102(87.93)$ & $3(2.59)$ & \\
\hline $\mathrm{EPDS} \geq 10$ & $5(4.20)$ & $2(1.68)$ & NS & $3(2.70)$ & $0(0)$ & NS & $11(9.48)$ & $0(0)$ & NS \\
\hline
\end{tabular}

\footnotetext{
Note:

* p- Value for Fisher's exact test

$\mathrm{NS}=$ not significant $(\mathrm{p}>0.05)$
} 


\section{Acknowledgments}

The authors would like to thank Dr. Paola Bonzi, director of the Consultorio Familiare "Genitori Oggi" and CAV Mangiagalli of Milan, for her constant sustain in this research and for her ability to stay close empathically. The authors also especially acknowledge the midwives of the Department of Obstetrics and Gynecology and the nurses of Neonatology Unit of Fondazione IRCCS Cà Granda - Ospedale Maggiore Policlinico, Milan, in particular Rosa Restieri and Mariangela Negri, for their availability and collaboration.

\section{References}

[1] Areias M E, Kumar R, Barros H \& Figueiredo E (1996) Correlates of postnatal depression in mothers and fathers. British Journal of Psychiatry, 169, 36-41. http://dx.doi.org/10.1192/bjp.169.1.36.

[2] Baldoni F (2005) Funzione paterna e attaccamento di coppia: L'importanza di una base sicura, in: N Bertozzi \& C Hamon (Eds.) Padri \& Paternità. Ed. Junior: Bergamo, 79-102.

[3] Baldoni F, Baldaro B \& Benassi M G (2009) Affective disorders and illness behaviour in perinatal period: Correlation between fathers and mothers. Child Development \& Disability XXXVI, 3, 25-44.

[4] Baldoni F \& Ceccarelli L (2010) La depressione perinatale paterna: Una rassegna della ricerca clinica ed empirica. Infanzia $e$ Adolescenza, 9, 79-92.

[5] Benvenuti P, Ferrara M, Niccolai C, Valoriania V \& Cox J (1999) The Edinburgh Postnatal Depression Scale: Validation for an Italian sample. Journal of Affective Disorder, 53, 137-141. http://dx.doi.org/10.1016/S0165-0327(98)00102-5.

[6] Buist A, Morse C a \& Durkin S (2002) First-time parenthood: Influences on pre-and postnatal adjustment in fathers and mothers. Journal of Psychosomatic Obstetrics \& Gynecology, 21, 109-120.

[7] Burt V K \& Stein K (2002) Epidemiology of depression throughout the female life cycle. Journal of Clinical Psychiatry, 63, 9- 15.

[8] Condon J T, Boyce P \& Corkindale C J (2004) the first-time fathers study: A prospective study of the mental health and wellbeing of men during the transition to parenthood. Australian and New Zealand Journal of Psychiatry, 38, 56-64. http://dx.doi.org/10.1111/j.1440 1614.2004.01298.x

[9] Cowan P a \& Cowan C P (1992) when partners become parents, Basic Books: New York.

[10]Cox J, Holden J \& Sagovsky R (1987) Detection of postnatal depression: Development of the 10-item Edinburgh Postnatal Depression Scale. British Journal of Psychiatry, 150, $782-786$ http://dx.doi.org/10.1192/bjp.150.6.782.

[11]Currò V, De Rosa E, Maulucci S, Maulucci M L, Silvestri M T, Zambrano A \& Regine V (2009) The use of Edimburgh Postanatal Depression Scale to identify postnatal depression symptoms at well child visit. Italian Journal of Pediatrics, $35, \quad 1-9$ http://dx.doi.org/10.1186/1824-7288-35-32.

[12]De Magistris A, Carta M \& Fanos V (2013) postpartum depression and the male partner. Journal of Pediatric and Neonatal Individualized Medicine, 2, 15-27.

[13]Edhborg M (2008) Comparison of different instruments to measure blues and to predict depressive symptoms 2 months postpartum: A study of new mothers and fathers. Scandinavian Journal Caring Sciences, $\quad 2, \quad 186-195 . \quad$ http://dx.doi.org/10.1111/j.14716712.2007.00512.x.

[14]Edhborg M, Matthiesen A S, Lundh W \& Widstrom a M (2005) Some early indicators for depressive symptoms and bonding 3 months postpartum: A study of new mothers and fathers. Archives of Women's of Mental Health, 8, 221-231. http://dx.doi.org/10.1007/s00737-0050097-5.

[15]Edmondson O J, Psychogiou L, Vlachos H, Netsi E \& Ramchandani P G (2010) Depression in fathers in the postnatal period: Assessment of the Edinburgh Postnatal Depression Scale as a screening measure. Journal of Affective Disorders, 125, 365-368. http://dx.doi.org/10.1016/j.jad.2010.01.069.

[16]Escribà-Agüir V \& Artazcoz L (2011) Gender differences in postpartum depression: A longitudinal cohort study. Journal of Epidemiology \& Community Health, 65, 320-326. http://dx.doi.org/10.1136/jech.2008.085894.

[17]Figueiredo B \& Conde A (2011) Anxiety and depression symptoms in women and men from early pregnancy to 3 -months postpartum: Parity differences and effects. Journal of Affective Disorders, 132, 146-157. http://dx.doi.org/10.1016/i.jad.2011.02.007.

[18] Gao L L, Chan S W \& Mao Q (2009) Depression, perceived stress, and social support among first-time Chinese mothers and fathers in the postpartum period. Research in Nursing \& Health, 32, 50-58. http://dx.doi.org/10.1002/nur.20306

[19]Gawlik S, Müller M, Hoffman L, Dienes A, Wallwiener M, Sohn C, Schlehe B \& Reck C (2014) Prevalence of paternal perinatal depressiveness and its link to partnership satisfaction and birth concerns. $\mathrm{Ar}$ chives of Women's of Mental Health, 17, 49-56. http://dx.doi.org/10.1007/s00737-013-0377-4.

[20]Goodman J H (2004) paternal postpartum depression, its relationship to maternal postpartum depression, and its implications for family health. Journal of Advanced Nursing, 45, 26-35. http://dx.doi.org/10.1046/j.1365-2648.2003.02857.x.

[21] Goodman J H (2008) Influences of maternal postpartum depression on fathers and fathers-infant interaction. Infant Mental Health Journal, 29, 624-643. http://dx.doi.org/10.1002/imhj.20199.

[22]Jacob T \& Johnson S L (1997) Parent-child interaction among depressed fathers and mothers: Impact on child functioning. Journal of Family Psychology, 11, 391-409. http://dx.doi.org/10.1037/08933200.11.4.391.

[23] Johnson M P \& Baker S R (2004) Implications of coping repertorie as men's stress, anxiety and depression following pregnancy, childbirth and miscarriage: A longitudinal study. Journal of Psychosomatic $\mathrm{Ob}$ $\begin{array}{lllll}\text { stetrics } \quad \text { G } & \text { Gnecology, } & \text { 25, }\end{array}$ http://dx.doi.org/10.1080/01674820412331282240.

[24]Luca D \& Bydlowski M (2001) Dépression pater nelle et périnatalité. Le Carnet/Psy, 67, 28-33. http://dx.doi.org/10.3917/lcp.067.0028.

[25] Matthey S, Barnett B, Ungerer J \& Waters B (2000). Paternal and maternal depressed mood during the transition to parenthood. Journal of Affective Disorders, 60, 75-85. http://dx.doi.org/10.1016/S01650327(99)00159-7.

[26] Matthey S, Barnett B, Kavanagh D J \& Howie P (2001) Validation of the Edinburgh Postnatal Depression Scale for men, and comparison of item endorsement with their partners. Journal of Affective Disorders, 64, 175-184. http://dx.doi.org/10.1016/S0165-0327(00)00236-6.

[27]Morse C A, Buist a \& Durkin S (2000) First-time parenthood: Influences on pre- and postnatal adjustment in fathers and mothers. Journal of Psychosomatic Obstetrics \& Gynecology, 21, 109-120. Nishimura a \& Ohashi K (2010) Risk factors of paternal depression in the early postnatal period in Japan. Nursing \& Health Science, 12, 2, 170-176.

[28]Paulson JF \& Bazemore S D (2010) Prenatal and postpartum depression in fathers and its association with maternal depression: A metaanalysis. Journal of American Medical Association, 303, 1961-1969. http://dx.doi.org/10.1001/jama.2010.605.

[29]Pinheiro R T, Magalhães P V S, Horta B L, Pinheiro K A T, Da Silva $\mathrm{R}$ a \& Pinto R H (2006) Is paternal postpartum depression associated with maternal postpartum depression? Population-based study in Brazil. Acta Pediatrica Scandinavica, 113, 283-232. http://dx.doi.org/10.1111/j.1600-0447.2005.00708.x.

[30]Ramchandani P G, O'Connor T G, Evans J, Heron J, Murray L \& Stein A (2008a) The effects of pre- and postnatal depression in fathers: A natural experiment comparing the effects of exposure to depression on offspring. Journal of Child Psychology and Psychiatry, 49, 1069-1078. http://dx.doi.org/10.1111/j.1469-7610.2008.02000.x.

[31]Ramchandani P G, Stein A, O'Connor T G, Heron J, Murray L \& Evans J (2008b) Depression in men in the postnatal period and later child psychopathology: A population cohort study. Journal of the American Academy of Child \& Adolescent Psychiatry, 47, 390-398. http://dx.doi.org/10.1097/CHI.0b013e31816429c2.

[32] Ramchandani P G, Psychogiou L, Vlachos H, Iles J, Sethna V, Netsi E \& Lodder A (2011) Paternal depression: An examination of its links with father, child and family functioning in the postnatal period. Depression and Anxiety, 28, 471-477. http://dx.doi.org/10.1002/da.20814.

[33] Schumacher M, Zubaran C \& White G (2008) Bringing birth-related paternal depression to the fore. Women Birth, 21, 65-70. http://dx.doi.org/10.1016/j.wombi.2008.03.008.

[34] Solantaus T \& Salo S (2005) Paternal Postnatal Depression: Fathers emerged from the wings. The Lancet, 365, 2158-2159. http://dx.doi.org/10.1016/S0140-6736(05)66754-2.

[35] Van den Berg M P, Van den Ende J, Crijnen A A M, Jaddoe V W V, Moll H A, Mackenbach J P, Hofman A, Hengeveld M W, Tiemeier H \& Verhulst F C (2009) Paternal depressive symptoms during pregnancy are related to excessive infant crying. Pediatrics, 124, 96-103. http://dx.doi.org/10.1542/peds.2008-3100.

[36] Wee K Y, Skouteris H, Pier C, Richardson B \& Milgrom J (2011) Correlates of ante- and postnatal depression in fathers: A systematic 
review. Journal of Affective Disorders, 130, 358-377. http://dx.doi.org/10.1016/j.jad.2010.06.019.

[37]Weitzman M, Rosenthal D G \& Liu Y H (2011) Paternal depressive symptoms and child behavioral or emotional problems in the United States. Pediatrics, 128, 1126-1134 http://dx.doi.org/10.1542/peds.2010-3034.

[38] Wilhem K, Parker G \& Dewhurst J (1998) Examining sex differences in the impact of anticipated and actual life events. Journal of Affective Disorders, 48, 37-45. $\quad$ http://dx.doi.org/10.1016/S01650327(97)00138-9.

[39]Zelkowitz P \& Milet T H (2001) the course of postpartum psychiatric disorders in women and their partners. Journal of Nervous and Mental Disease, 189, 575-582. $\quad$ http://dx.doi.org/10.1097/00005053200109000-00002. 